\title{
Polytetrafluoroethylene Patch versus Autologous Pericardial Patch for Right Ventricular Outflow Tract Reconstruction in Patients with Tetralogy of Fallot
}

\author{
Sachin Talwar1, Intekhab Alam¹, Vishnubhatla Srreenivas², Palleti Rajashekar1, \\ Sivasubramanian Ramakrishnan ${ }^{3}$, Shiv Kumar Choudhary', Balram Airan1 \\ ${ }^{1}$ Department of Cardiothoracic and Vascular Surgery \\ ${ }^{2}$ Biostatistics, All India Institute of Medical Sciences, New Delhi, India \\ ${ }^{3}$ Cardiology, All India Institute of Medical Sciences, New Delhi, India \\ Email: sachintalwar@hotmail.com
}

How to cite this paper: Talwar, S., Alam, I., Srreenivas, V., Rajashekar, P., Ramakrishnan, S., Choudhary, S.K. and Airan, B. (2017) Polytetrafluoroethylene Patch versus Autologous Pericardial Patch for Right Ventricular Outflow Tract Reconstruction in Patients with Tetralogy of Fallot. World Journal of Cardiovascular Surgery, 7, 41-53. https://doi.org/10.4236/wjcs.2017.73006

Received: February 21, 2017

Accepted: March 28, 2017

Published: March 31, 2017

Copyright (c) 2017 by authors and Scientific Research Publishing Inc. This work is licensed under the Creative Commons Attribution International License (CC BY 4.0).

http://creativecommons.org/licenses/by/4.0/

\begin{abstract}
Objective: For patients of TOF with pulmonary annular hypoplasia, reconstruction of right ventricular outflow tract (RVOT) often requires a trans annular patch (TAP). The present study aims to compare the outcomes of TOF repair using Polytetrafluoroethylene (PTFE) patch versus autologous glutaraldehyde fixed pericardial patch for RVOT reconstruction. Materials and methods: 103 consecutive patients undergoing TOF repair in whom TAP was required were randomized into two groups: Group I (pericardial patch), Group II (PTFE patch). Postoperative outcomes in terms of postoperative heart rhythm, duration of mechanical ventilation, mediastinal and pleural drainage, length of stay in intensive care unit (ICU) and hospital mortality were assessed. A separate team of cardiologists independently evaluated pre- and post-operative gradients across the RVOT, degree of pulmonary insufficiency, right ventricular systolic function. Results: There were no significant differences between the two groups in terms of the incidence of postoperative arrhythmias, duration of mechanical ventilation, length of intensive care unit or hospital stay. The requirement of inotropes was no different in the PTFE patch group as compared with the pericardial patch group (16.84 \pm 7.04 vs. $17.90 \pm$ 6.71 , median 19 vs. $20, \mathrm{p}=0.825)$. The re-exploration rate was higher in the PTFE group as compared with the pericardial patch group (6 vs. 1). Postoperative Echocar-diography revealed no differences in the RV systolic function between the two groups before discharge. Conclusion: In patients undergoing TOF repair, using a PTFE patch yields comparable results. However, the efficacy of PTFE will only be established once; mid-term and long-term results
\end{abstract}


are available.

Keywords

Tetralogy of Fallot, Right Ventricular Outflow Tract, Patch Material

\section{Introduction}

Of all the cyanotic heart conditions, Tetralogy of Fallot (TOF) is the most common which is found in $3.5 \%$ of all infants born diagnosed with a congenital heart defect [1]. In 1955, for the first time, intracardiac corrective surgery of TOF was performed [2]. Before 1955, the survival rate was dismal in the first year of life with only $50 \%$ surviving the operation. Only a few of the patients used to survive into adulthood [3]. However, results have improved now gradually [4] [5] [6]. Consequently, an increasingly greater number of patients with TOF now survive well into adulthood.

The surgical approach to TOF repair has constantly evolved over the years. In the earlier era, often after initial palliative systemic to pulmonary artery shunts, TOF repair used to be performed via right ventriculotomy, usually combined with a patch in the right ventricular outflow tract (RVOT). The focus has now shifted to a trans atrial-trans pulmonary approach as primary repair of choice [7]. The enthusiasm that had led to the adoption of the latter approach was to negate the unfavorable side effects seen commonly after ventriculotomy, such as coronary artery damage and trans mural myocardial scarring. These factors were believed to be responsible for causing long-term impairment of right ventricular function. They are also implicated as a risk factor for ventricular arrhythmias [8]. Predictors of poor long-term outcomes after TOF repair have been studied extensively over a period of time and include the degree of residual pulmonary regurgitation (PR), left and right ventricular size and function, myocardial tissue composition, electrical inhomogeneity and right ventricular outflow function [8] [9] [10] [11] [12].

Great variance is seen among patients of TOF, who present with a diverse anatomical spectrum of the VSD and RVOT, including the pulmonary valve and annulus that often necessitates tailoring the surgical technique to suit the individual patient's anatomy. Therefore, a trans annular patch (TAP) may at times be unavoidable in patients with a very restrictive and small pulmonary valve annulus/RVOT. However, even in the latter subset, large TAPs are currently avoided to prevent the deleterious long-term effects of free PR [9].

RVOT augmentation (TAP) has been performed using many of the commonly used patch materials such as autologous glutaraldehyde fixed pericardium, unfixed autologous or bovine pericardium, homograft with some valves and various synthetic patches. The choice of aforementioned materials is mostly a matter of surgeon preference. There have not been many studies comparing unfixed pericardium with glutaraldehyde fixed pericardium [13] [14]. The information so obtained can be potentially useful for choosing the best patch material for RVOT 
reconstruction. Such a material should be inexpensive, easy to handle, should not form aneurysms, should not undergo undue calcification and should preserve the right ventricular function. This study was therefore, designed to address these issues. The aim was to compare the clinical outcomes of TOF repair in patients requiring RVOT augmentation using a transannular patch using either a glutaraldehyde fixed autologous pericardial patch to that of a patch of expanded Polytertrafluroethylene (PTFE).

\section{Patients and Methods}

\subsection{Patients}

A total of 103 consécutive patients, aged 1 - 16 years undergoing intracardiac repair of TOF at the All India Institute of Medical Sciences, New Delhi, India, were included in the study. All the enrolled patients had a narrow pulmonary annulus and needed a TAP as assessed pre-operatively and was confirmed later intraoperatively $(\mathrm{Z}<-3)$. These patients were randomized into two groups: Group I (pericardial patch), Group II (PTFE patch), based on withdrawal of lots once the decision to perform a TAP repair had been confirmed in the operating room. The study protocol was duly approved by the ethics committee of the Institute and informed consent was obtained from the parents of all the patients in the study. The study was designed and the sample size was calculated to achieve a minimum statistical power of 0.9 .

\subsection{Surgery and Anesthesia}

Anesthesia was induced and maintained by weight-related doses of thiopental, fentanyl, midazolam and relaxant like rocuronium and vecuronium. All patients received cefazolin as antibiotic prophylaxis after induction of anesthesia and during the next $48-72 \mathrm{~h}$ till the removal of all invasive lines and catheters. Cardio pulmonary bypass (CPB) was carried out using a non-pulsatile roller pump, membrane oxygenators and standard (uncoated) extracorporeal circuits under mild hypothermia $\left(32^{\circ} \mathrm{C}\right)$. The circuit was primed with required amounts of Ringer's Lactate solution, mannitol and sodium bicarbonate. Desired hematocrit value was maintained by adding blood or removing it. Delnido solution was used for cardioplegia in the antegrade route for all the patients.

Intra-operative transoesophaeal echocardiography (TEE) was performed in all patients to confirm the diagnosis and to assess the pulmonary annulus and the need for placement of an outflow patch. Surgery was performed in the standard manner through a midline sternotomy and aorto-bicaval cannulation for institution of CPB. Right atrium (RA) was opened after snugging venous cannulae and left heart was vented through the interatrial septum. The VSD was closed with a Dacron patch and infundibular resection was performed either trans RA or trans RVOT. An adequate size right ventriculotomy was then made and extended across the pulmonary annulus taking care to preserve as much of the native pulmonary valve apparatus as possible.

For a patient, who had been randomized to the pericardial patch group (Group 
I), a patch of autologous pericardium was harvested before commencing CPB and was subsequently treated in $0.625 \%$ glutaraldehyde for 6 minutes to be used for TAP reconstruction. It was performed on an arrested heart using a continuous 6-0 polypropylene suture. In the PTFE group (Group II), a $0.6 \mathrm{~mm}$ thick PTFE patch was used, which was cut out of an appropriate size Gore-Tex graft for appropriate contouring. It was sutured in place using a continuous 6-0 PTFE suture to minimize needle hole bleeding.

All patients were started on low dose of Dobutamine with or without low dose dopamine at the time of rewarming and $\mathrm{CPB}$ was weaned off gradually. Requirement of additional vasopressors was basedon the current systemic blood pressure. Vasodilators in the form of nitroglycerin or sodium nitroprusside were alsoadded depending on the systemic blood pressure, measured post CPB $p$ RV/LV, and intraoperative TEE. Intraoperative TEE was always performed for any residual VSD, gradient across the RVOT, any tricuspid regurgitation etc. Post-repair pR$\mathrm{V} / \mathrm{LV}$ was always measured using a needle and a ratio of $\leq 0.7$ was accepted.

\subsection{Post-Operative Care}

All patients were transferred to cardiac surgical ICU after surgery. Here they were managed by a team comprising cardiac surgeons, cardiac intensivists, anesthesiologist and pediatric cardiologist. Patients were fully optimized and then extubated. We followed a policy of early extubation unless signs of LCOS (low cardiac output syndrome) were seen. Inotropic requirement was optimized as per status of the patient and the dose and duration of the inotropic support was recorded carefully. Postoperative parameters that were assessedand were recorded included rhythm (any type of arrhythmia), number and amount of inotropic support, duration of mechanical ventilation, duration of ICU and hospital stay. Inotropic requirement was assessed in terms of the standard inotropic score that was calculated as follows:

Inotropic score $=$ dose in $\mathrm{mcg} / \mathrm{kg} / \mathrm{min}$ of (dopamine + dobutamine $) \times 1+\mathrm{mi}$ lrinone $\times 30+($ epinephrine + norepinephrine $) \times 100$ [15] .

A separate team of cardiologists who were blinded to the nature of the patch material performed post-operative echocardiography. The echocardiographic parameters included during this time were: Tricuspid annular plane systolic excursion (TAPSE) in $\mathrm{cm}$, RV fractional area change as calculated from the systolic and diastolic dimensions of RV in the apical four chamber view, the pre- and post-operative gradient using continuous Doppler across RVOT, post-operative main pulmonary arterial dimension and postoperative grade of $P R$.

PR was graded as mild: regurgitant jet below the pulmonary valve, Moderate: jet in the RVOT with retrograde diastolic flow in the main pulmonary artery and Severe: retrograde diastolic flows in both pulmonary artery branches.

\subsection{Statistical Analysis}

As indicated above, the study was designed and the sample size was calculated to achieve a minimum statistical power of 0.9 by a qualified statistician (VB). Sta- 
tistical analysis was performed using SPSS 19 software (IBM SPSS v. $23^{\circledR}$ (SPSS Inc, Armonk, NY). Values are presented as mean \pm standard deviation (SD) or median for quantitative variables and $\mathrm{n}(\%)$ for qualitative variables. Comparisons between subgroups for continuous data were made with student $t$ test if normally distributed and Mann Whitney $U$ test otherwise. Tests between subgroups for qualitative data were made with Pearson chi-square test. 2 tailed $p<0.05$ was considered statistically significant.

\section{Results}

\subsection{Preoperative Baseline Characteristics}

51 patients underwent intracardiac repair of Tetralogy of Fallot with PTFE as the TAP material and 52 patients underwent intracardiac repair with glutaraldehyde fixed pericardial patch as the TAP material during the same period.

Based on preoperative baseline characteristics, summarised in Table 1 and $\mathrm{Ta}$ ble 2, both the groups were found to be similar. Echocardiographically, there

Table 1. Preoperative characteristics of the two groups.

\begin{tabular}{|c|c|c|c|c|}
\hline Parameters & $\begin{array}{c}\text { Fixed } \\
\text { pericardial patch }\end{array}$ & PTFE patch & Total & $P$ value \\
\hline Numbers (n) & 52 & 50 (1mortality) & 102 analyzed & \\
\hline \multicolumn{5}{|l|}{ Age (years) } \\
\hline Mean \pm SD & $5.61 \pm 3.36$ & $5.98 \pm 4.74$ & $5.79 \pm 4.05$ & \\
\hline Median & 4 & 5 & 4 & 0.158 \\
\hline $\operatorname{Min}-\max$ & $1-16$ & $2-15$ & $1-16$ & \\
\hline \multicolumn{5}{|l|}{ Weight $(\mathrm{kg})$} \\
\hline Mean \pm SD & $17.27 \pm 10.65$ & $18.70 \pm 9.87$ & $17.88 \pm 10.13$ & \\
\hline Median & 14 & 16 & 15 & 0.236 \\
\hline Min - Max & $6-45$ & $6-43$ & $6-45$ & \\
\hline $\operatorname{Sex}(M: F)$ & $16: 13$ & $18: 10$ & $34: 23: 00$ & 0.57 \\
\hline \multicolumn{5}{|l|}{$\operatorname{BSA}\left(\mathrm{m}^{2}\right)$} \\
\hline Mean & $0.621 \pm 0.456$ & $0.731 \pm 0.390$ & $0.686 \pm 0.391$ & 0.612 \\
\hline Median & 0.657 & 0.749 & 0.688 & \\
\hline Min-Max & $0.352-1.458$ & $0.369-1.563$ & $0.352-1.563$ & \\
\hline \multicolumn{5}{|l|}{ Cyanosis } \\
\hline Mild (SpO2 >85\%) & $41(\mathrm{n})$ & 40 & 81 & \\
\hline Severe $(\mathrm{SpO} 2<85 \%)$ & 11 & 10 & 21 & 0.415 \\
\hline \multicolumn{5}{|l|}{ Diagnosis } \\
\hline TOF & 34 & 36 & 70 & 0.526 \\
\hline DORV + PS & 18 & 14 & 32 & \\
\hline Previous shunt & 4 & 5 & 9 & 0.761 \\
\hline
\end{tabular}

SD indicates standard deviation from the mean calculated by using the SPSS 19 software. P values were not significant in either group. 
was only one patient in the PTFE group who had RV dysfunction on postoperative echocardiography, as evidenced by Tricuspid annular plane systolic excursion (TAPSE $<-2$ SD). Though, the fractional area change (FAC) was normal in this patient.

\subsection{Intraoperative and Post-Operative Immediate Outcomes}

Of the 103 patients operated, there was one death in the PTFE group. This was a 5 -year-old patient, who underwent intracardiac repair after coil embolization of significant aorto-pulmonary collaterals. He was weaned off $\mathrm{CPB}$ with acceptable post-operative/LV (0.6). He was extubated after 6 hours and remained stable. But, he suddenly developed pulmonary hemorrhage, leading to aspiration and asphyxia. During ongoing resuscitation, he sustained cardiorespiratory arrest and was placed on extra corporeal membrane oxygenation (ECMO) support. But he developed DIC and subsequently expired on post-operative day 3. For statistical analysis, this patient was excluded from the study. In another patient coil embolization performed and was followed by intracardiac repair. He too was weaned off from CPB with acceptable PRV/LV. In the post-operative period, they underwent into severe LCOS. This patient then underwent tracheostomy, and was weaned off gradually. Later on, he had a Methicillin resistant Staphylococcus aureus (MRSA) infection at the cannula site and developed necrotizing fasciitis of the forearm. He later recovered gradually (Table 3).

The mean CPB time in the pericardial patch group was $98.15 \pm 15.63$ (median 94.5) minutes against $96.92 \pm 13.58$ (median 95.6) minutes in the PTFE group (p $=0.971)$. The mean aortic cross clamp time in pericardial patch group was 57.67 \pm 17.23 (median-56) vs. $62.02 \pm 10.49$ (median-60) minutes $(\mathrm{p}=0.456)$. No major arrhythmias occurred intraoperatively. Only 5 patients required cardioversion on

Table 2. Preoperative echocardiographic parameters.

\begin{tabular}{ccccc}
\hline Parameter & $\begin{array}{c}\text { Fixed pericardial } \\
\text { patch }\end{array}$ & PTFE patch & Total & P value \\
& & & & \\
Trans pulmonary & & & & \\
gradient (mm Hg) & $68.56 \pm 13.05$ & $69.41 \pm 12.97$ & $67.75 \pm 13.77$ & \\
Mean \pm SD & 69 & 67 & 66 & 0.243 \\
Median & $42-97$ & $44-93$ & $42-97$ & \\
Min - Max & & & & \\
& & & & \\
Fractional area change & $0.613 \pm 0.25$ & $0.596 \pm 0.19$ & $0.607 \pm 0.17$ & \\
Mean \pm SD & 0.59 & 0.55 & 0.56 & 0.097 \\
Median & $0.52-0.68$ & $0.49-0.65$ & $0.49-0.68$ & \\
Min - Max & & & & \\
& & & & \\
TAPSE (cm) & $1.81 \pm 0.52$ & $1.92 \pm 0.16$ & $1.88 \pm 0.34$ & \\
Mean \pm SD & 1.74 & 1.80 & 1.77 & 0.78 \\
Median & $1.39-2.4$ & $1.40-2.3$ & $1.39-2.4$ & \\
Min - Max & & & & \\
& & & & \\
\hline
\end{tabular}

SD indicates standard deviation from the mean calculated by using the SPSS 19 software. P values were not significant in either group. 
Table 3. Postoperative characteristics.

\begin{tabular}{|c|c|c|c|c|}
\hline Parameters & $\begin{array}{l}\text { Fixed pericardial } \\
\text { patch }\end{array}$ & PTFE patch & Total & $\mathrm{P}$ value \\
\hline \multicolumn{5}{|l|}{$\begin{array}{c}\text { Mechanical } \\
\text { ventilation (hrs) }\end{array}$} \\
\hline Mean \pm SD & $7.23 \pm 2.61$ & $7.84 \pm 3.7$ & $7.54 \pm 2.84$ & \multirow{3}{*}{0.729} \\
\hline Median & 7 & 8 & 8.2 & \\
\hline Min - Max & $5.1-19.3$ & $4.8-23.7$ & $4.8-23.7$ & \\
\hline \multicolumn{5}{|l|}{ ICU stay (hrs) } \\
\hline Mean \pm SD & $49.60 \pm 19.25$ & $48.66 \pm 22.80$ & $49.13 \pm 21.03$ & \multirow{3}{*}{0.481} \\
\hline Median & 50 & 47.9 & 48.6 & \\
\hline Min - Max & $28.5-132.5$ & $27.4-130.2$ & $27.4-132.5$ & \\
\hline \multicolumn{5}{|l|}{ Hospital stay (days) } \\
\hline Mean \pm SD & $6.02 \pm 1.23$ & $5.89 \pm 2.16$ & $5.96 \pm 1.70$ & \multirow{3}{*}{0.792} \\
\hline Median & 6 & 6.4 & 6.1 & \\
\hline Min - Max & $5-10$ & $5-15$ & $5-15$ & \\
\hline \multicolumn{5}{|c|}{ Mediastinal drainage (ml) } \\
\hline Mean \pm SD & $155 \pm 50$ & $175 \pm 55$ & $160 \pm 65$ & \multirow{3}{*}{0.846} \\
\hline Median & 105 & 120 & 110 & \\
\hline Min - Max & $50-250$ & $70-350$ & $50-350$ & \\
\hline \multicolumn{5}{|l|}{ Inotropic score } \\
\hline Mean \pm SD & $17.90 \pm 6.71$ & $16.78 \pm 7.04$ & $18.33 \pm 7.88$ & \multirow{3}{*}{0.825} \\
\hline Median & 20 & 19 & 20 & \\
\hline Min - Max & $5-30$ & $5-37$ & $5-37$ & \\
\hline JET & 14 & 17 & 31 & \multirow{3}{*}{0.928} \\
\hline Sinus tachycardia & 7 & 5 & 12 & \\
\hline bradycardia & 2 & 1 & 3 & \\
\hline \multicolumn{5}{|l|}{ Pleural effusion } \\
\hline$<2$ days & 13 & 10 & 23 & \\
\hline$>2$ days & 4 & 9 & 13 & 0.590 \\
\hline
\end{tabular}

SD indicates standard deviation from the mean calculated by using the SPSS 19 software. P values were not significant in either group.

releasing aortic cross clamp. The mean duration of mechanical ventilation was $7.23 \pm 2.61$ (median-7) hours in pericardial patch group and $7.84 \pm 3.7$ (median8 ) hours in the PTFE group $(\mathrm{p}=0.743)$. The mean duration of ICU stay and hospital stay in the pericardial patch group were $49.60 \pm 19.25$ (median-50) hours and $6.02 \pm 1.23$ days respectively. In the PTFE group, same duration was $48.66 \pm$ 22.80 (median-47.9) hours and $5.89 \pm 2.16$ days respectively $(\mathrm{p}>0.05)$. The amount of mediastinal drainage also did not differ significantly in the 2 groups. There were 10 re-explorations for increased mediastinal drainage, 3 in the pericardial patch group vs. 7 in the PTFE patch group. The site of bleeding in these patients was in transannular patch in the pericardial patch. Out of the 7 re-explorations in the PTFE group, 4 were from the patch site and 3 were from unrelated sites. The mean inotropic score in the pericardial patch group was $17.90 \pm 6.71$ (median-20) and in the PTFE group was $16.78 \pm 7.04$ (median-19). This was also not statistically significant $(\mathrm{p}=0.825)$. 


\subsection{Echocardiographic Findings}

Post-op3 patients had right ventricular dysfunction in the immediate postoperative period (all in PTFE patch group). Two had moderate and one had severe PR. Mean RVOT gradient after surgery was $16.78 \pm 7.61$ in the pericardial patch group as against $15.21 \pm 6.84$ in the PTFE patch group (Table 4).

In the pericardial patch group, 32 patients had mild PR and 16 had moderate PR and 4 had severe PR while In the PTFE patch the values were 27, 18 and 5 respectively. None of these patients had poor anatomy in the form of poor McGoon's ratio or small sized pulmonary arteries preoperatively.

\section{Discussion}

Autologous pericardium whether fixed or unfixed is being harvested for many of the cardiovascular procedures for varied reconstructions. Autologous pericardium confers a lot of advantages such as non-porosity, easy availability, conformability, lack of bleeding through needle holes and ease of use. Autologous pericardium is a readily available biomaterial that is free of donor-derived infections and also there is a lack of any immune response to it. Unlike many of the other materials, it is less likely to be responsible for causing thrombosis or hemolysis. Despite this, there are many disadvantages that confer poor handling characteristics [16], limiting its universal application in cardiovascular surgery. This includes onset of tissue stretching or shrinkage several years later after im-plantation has been done. The pericardium used may become retracted and fibrotic, also exhibiting progressive thinning with dilatation and ultimately leading to the formation of aneurysm [17]. When fresh pericardium was used as a

Table 4. Post-operative echocardiographic parameters.

\begin{tabular}{|c|c|c|c|c|}
\hline Parameters & Fixed pericardial patch & PTFE patch & Total & $P$ value \\
\hline \multicolumn{5}{|c|}{ Post op PS gradient (mm Hg) } \\
\hline Mean \pm SD & $16.78 \pm 7.61$ & $15.21 \pm 6.84$ & $15.97 \pm 7.02$ & \\
\hline Median & 19.2 & 18 & 17 & 0.587 \\
\hline Min - Max & $7-32$ & $5-30$ & $5-32$ & \\
\hline \multicolumn{5}{|c|}{ Post op TAPSE (cm) } \\
\hline Mean & $1.49 \pm 0.34$ & $1.55 \pm 0.27$ & $1.51 \pm 0.39$ & \\
\hline Median & 1.43 & 1.52 & 1.67 & 0.433 \\
\hline Min - Max & $1-2.2$ & $1.2-2.3$ & $1-2.3$ & \\
\hline \multicolumn{5}{|c|}{ Fractional area change (\%) } \\
\hline Mean & $0.682 \pm 0.12$ & $0.649 \pm 0.09$ & $0.665 \pm 0.10$ & \\
\hline Median & 0.701 & 0.67 & 0.686 & \\
\hline Min - Max & $0.46-0.732$ & $0.42-0.702$ & $0.42-0.732$ & 0.184 \\
\hline \multicolumn{5}{|c|}{ Post-operative PR (n) } \\
\hline Mild & 32 & 27 & 59 & \\
\hline \multirow{2}{*}{ Severe } & 16 & 18 & 34 & 0.653 \\
\hline & 4 & 5 & 9 & \\
\hline
\end{tabular}

SD indicates standard deviation from the mean calculated by using the SPSS 19 software. P values were not significant in either group. 
patch in the cusps or as artificial chordae during valvular reconstruction, frequent retraction and fibrosis were observed. The use of pericardium for closing large ventricular septal defects or as patch for reconstruction of the right ventricular outflow tract was found to result in an aneurysmal change [18]. Also, pediatric patients often have to undergo multiple surgical procedures. Dense fibrosis and loss of tissue planes during such redo-surgeries pose a technical challenge to the surgeon to conduct a safe procedure, limiting use of unfixed autologous pericardium. To overcome the limitations of unfixed pericardial patch, fixation using glutaraldehyde of the pericardium, and then its usage was advocated during RVOT reconstruction. The advantage of using a glutaraldehyde fixed pericardium as a patch includes limited stretching post operatively and good handling characteristics. Messina et al compared glutaraldehyde fixed pericardial patch to conventional autologous unfixed pericardium for reconstruction of RVOT. At 6 months follow up, the unfixed pericardial patch cohort showed dilatation of RVOT by independent observers [13]. Other studies have also demonstrated the propensity of unfixed pericardial patch to dilate and also cause RVOT aneurysms in the late postoperative period. This may contribute to the increase in severity of PR progression after TAP repair [16] [17] [19] and there is an increase in risk of calcification [20] [21] [22]. This may potentially obtund the enthusiasm surrounding its usage by causing residual RVOTO and PR. Studies have also reported that the efficacy of TAP depends on an optimal size of the patch: if it's too large, it will cause regurgitation, and if too small a patch will lead to stenosis. Tissue patches elicit varied degrees of immunogenicity. So, during redo-surgeries, tissue patches are often found to be calcified heavily, aneurismal or densely adhered to the adjacent structures [19].

To address these problems, a material which is non-degenerating, durable and non-immunologic like PTFE can be used for Right ventricular outflow tract reconstruction.

PTFE is chemically composed of carbon chains, which are saturated with fluorine. Its medical use started in 1960s, at first in artificial heart valves. The PTFE molecule is biologically stable, and the implants made out of it, does not undergo any biological deterioration within the body. The surface of PTFE is electronegative, which minimizes its reaction with blood components. PTFE has low thrombogenicity, on account of its aforementioned properties. There many advantages of PTFE such as good surgical handling, surface modification, and tissue in growth into the prostheses, low immunogenicity, and low porosity rate $85 \%$ - 95\%. Disadvantages of PTFE include pseudointimal hyperplasia at the anastomotic site, and uncommonly calcification [23] [24].

PTFE has been used as the preferred material as vascular graft in many of the procedures such as for construction of systemic arterial-pulmonary shunts in neonates with complex congenital cyanotic heart defects, as a part palliative procedure in case of interrupted aortic arch, for construction of extra-anatomic aortic by-pass and for total cavopulmonary connection. The PTFE patches are also used for closure of septal defects, reconstruction of the right and the left ventricular 
outflow tracts, as interposition or onlay graft for correction of coarctation of the aorta and repair of stenos sin the main pulmonary artery and its branches. PTFE membranes are very good pericardial substitutes after complex surgeries where valve replacement or the use of a valved conduit is used and redo-surgeries are anticipated. Itis believed that at re operation, these patches unlike pericardial patch would not be aneurysmal because of their rigid nature and the peel formed around the PTFE patch would help in preventing development of any dense adhesions with the adjacent structures. However, such a preposition about the PTFE patch needs to be proved scientifically, as compared to the time-tested pericardial patch. That's why, in this study we tried to test this preposition and compare the in-hospital outcome of TAP repair using either a PTFE patch or a glutaryldehyde fixed pericardial patch.

The preposition lead us to investigate, whether the claimed physical characteristics of PTFE actually translates out into biological effectiveness, when compared with pericardial patch. So, in the present study, there was no significant difference in the in-hospital variables studied, due to the usages of glutaraldehyde fixed pericardial patch and PTFE patch for reconstruction of RVOT. The favorable mechanical property of the PTFE patch and the early recovery of the myocardial function because of these properties, might explain these results. The increased number of re-exploration rate following placement of a PTFE patch was more than that of pericardial patch (6 against 1$)$, was seen only during the earlier course of the study, particularly when proline 5 - 0 sutures were used. The bleeding on reexplorations was seen mostly from the needle holes. This problem can be tackled with using a smaller sized needle or Gore-Tex suture.

In the present study, only 3 patients had post-operative right ventricular dysfunction as noted by a TAPSE $\mathrm{Z}$ score $<-2$ SD and also during reduced fractional area change of RV. On further evaluation, it was found that, these patients had intense preoperative cyanosis as the additional risk factor. They had a post op gradient across RVOT of 30, 18 and $22 \mathrm{~mm} \mathrm{Hg}$. Two of these patients ( $\Delta$ of $30 \mathrm{mmHg}$ and $18 \mathrm{mmHg}$ ) had moderate only pulmonary regurgitation and the 1 with $\Delta$ of $22 \mathrm{mmHg}$ had severe PR. We could not deduce any association between anatomic or physiological variables and progression of PR; it is assumed that progression of PR is an unwanted outcome of it, mainly because of the RVOT dynamics, such as increase in RVOT diameter with time. In view of this governing RVOT hemodynamics, we believe that the mechanical properties of PTFE such as the stiffness confers the natural advantage over the pericardial patch, by leading to reduced progression of dilatation and PR progression. This in total can lead to the preservation of RV function.

\section{Study Limitations}

The sample size was limited and variables evaluated out affecting the predictors of adverse outcomes after RVOT augmentation cannot be reliably drawn from this small study group. The RV dysfunction present initially and the residual PR seen in the patients, whether progresses or reaches to a plateau phase or improves 
upon over the period of time needs to be validated on long term studies to draw a definite advantage of PTFE over the pericardial patch. Further long term studies are required in view of these findings, so that only after which PTFE can virtually stake the claim of a better substitute than time tested pericardial patch.

\section{Conclusion}

In patients undergoing TOF repair, using a PTFE patch yields similar \& comparable results, as compared with the traditional usage of pericardial patch. However, the efficacy of PTFE will only be established once; mid-term and long-term results are available. Ideally the patch material of choice should be inexpensive, should not calcify or form aneurysms, should preserve the RV function and should not make re-operations difficult. These issues can be clarified only after a long-term meticulous follow-up of these patients.

\section{References}

[1] Mitchell, S.C., Korones, S.B. and Berendes, H.W. (1971) Congenital Heart Disease in 56,109 Births. Incidence and Natural History. Circulation, 43, 323-332.

https://doi.org/10.1161/01.CIR.43.3.323

[2] Lillehei, C.W., Cohen, M., Warden, H.E., Read, R.C., Aust, J.B., Dewall, R.A., et al. (1955) Direct Vision Intracardiac Surgical Correction of the Tetralogy of Fallot, Pentalogy of Fallot, and Pulmonary Atresia Defects: Report of First Ten Cases. Annals of Surgery, 142, 418-442. https://doi.org/10.1097/00000658-195509000-00010

[3] Bertranou, E.G., Blackstone, E.H., Hazelrig, J.B., Turner, M.E. and Kirklin, J.W. (1978) Life Expectancy without Surgery in Tetralogy of Fallot. The American Journal of Cardiology, 42, 458-466. https://doi.org/10.1016/0002-9149(78)90941-4

[4] Murphy, J.G., Gersh, B.J., Mair, D.D., Fuster, V., McGoon, M.D., Ilstrup, D.M., et al. (1993) Long-Term Outcome in Patients Undergoing Surgical Repair of Tetralogy of Fallot. The New England Journal of Medicine, 329, 593-599. https://doi.org/10.1056/NEJM199308263290901

[5] Hokanson, J.S. and Moller, J.H. (1999) Adults with Tetralogy of Fallot: Long-Term Follow-Up. Cardiology in Review, 7, 149-155. https://doi.org/10.1097/00045415-199905000-00012

[6] Nieminen, H.P., Jokinen, E.V. and Sairanen, H.I. (2009) Late Results of Pediatric Cardiac Surgery in Finland: A Population-Based Study with 96\% Follow-Up. Circulation, 104, 570-575. https://doi.org/10.1161/hc3101.093968

[7] Boni, L., Garcia, E., Galletti, L., Perez, A., Herrera, D., Ramos, V., et al. (2009) Current Strategies in Tetralogy of Fallot Repair: Pulmonary Valve Sparing and Evolution of Right Ventricle/Left Ventricle Pressures Ratio. European Journal of CardioThoracic Surgery, 35, 885-889; Discussion 889-890.

https://doi.org/10.1016/j.ejcts.2009.01.016

[8] Gatzoulis, M.A., Balaji, S., Webber, S.A., Siu, S.C., Hokanson, J.S., Poile, C., et al. (2000) Risk Factors for Arrhythmia and Sudden Cardiac Death Late after Repair of Tetralogy of Fallot: A Multicenter Study. The Lancet, 356, 975-981. https://doi.org/10.1016/S0140-6736(00)02714-8

[9] Al Habib, H.F., Jacobs, J.P., Mavroudis, C., Tchervenkov, C.I., O’Brien, S.M., Mohammadi, S., et al. (2010) Contemporary Patterns of Management of Tetralogy of Fallot: Data from the Society of Thoracic Surgeons Database. The Annals of Thoracic Surgery, 90, 813-820. https://doi.org/10.1016/j.athoracsur.2010.03.110 
[10] Sarris, G.E., Comas, J.V., Tobota, Z. and Maruszewski, B. (2012) Results of Reparative Surgery for Tetralogy of Fallot: Data from the European Association for Cardio-Thoracic Surgery Congenital Database. European Journal of Cardio-Thoracic Surgery, 42, 766-774. https://doi.org/10.1093/ejcts/ezs478

[11] Lindberg, H.L., Saatvedt, K., Seem, E., Hoel, T. and Birkeland, S. (2011) SingleCenter 50 Years' Experience with Surgical Management of Tetralogy of Fallot. European Journal of Cardio-Thoracic Surgery, 40, 538-542.

[12] D’Udekem, Y., Ovaert, C., Grandjean, F., Gerin, V., Cailteux, M., Shango-Lody, P., et al. (2000) Tetralogy of Fallot: Transannular and Right Ventricular Patching Equally Affect Late Functional Status. Circulation, 102, III116-III122. https://doi.org/10.1161/01.cir.102.suppl_3.iii-116

[13] Messina, J.J., O’Loughlin, J., Isom, O.W., Klein, A.A., Engle, M.A. and Gold, J.P. (1999) Glutaraldehyde Treated Autologous Pericardium in Complete Repair of Tetralogy of Fallot. Journal of Cardiac Surgery, 9, 298-303. https://doi.org/10.1111/j.1540-8191.1994.tb00848.x

[14] Scavo Jr., V.A., Turrentine, M.W., Aufiero, T.X., Sun, K., Binford, R., Carlos, G. and Brown, J.W. (1998) Monocusp Valve and Transannular Patch Reconstruction of the Right Ventricular Outflow Tract: An Experimental Study. ASAIO Journal, 44, M480-M485. https://doi.org/10.1097/00002480-199809000-00032

[15] Wernovsky, G., Wypij, D., Jonas, R.A., Mayer Jr., J.E., Hanley, F.L., Hickey, P.R., et al. (1995) Postoperative Course and Hemodynamic Profile after the Arterial Switch Operation in Neonates and Infants. A Comparison of Low-Flow Cardiopulmonary Bypass and Circulatory Arrest. Circulation, 92, 2226-2235. https://doi.org/10.1161/01.CIR.92.8.2226

[16] Seybold-Epting, W., Chiariello, L., Hallman, G.L. and Cooley, D.A. (1977) Aneurysm of Pericardial Right Ventricular Outflow Tract Patches. The Annals of Thoracic Surgery, 24, 237-240. https://doi.org/10.1016/S0003-4975(10)63749-6

[17] Peer, S.M., Bhat, P.S.S., Furtado, A.D. and Chikkatur, R. (2012) Right Ventricular Outflow Tract Aneurysm with Thrombus. Interactive Cardiovascular and Thoracic Surgery, 14, 488-490. https://doi.org/10.1093/icvts/ivr151

[18] Kawashima, Y., Nakano, S., Kato, M., Danno, M. and Sato, K. (1974) Fate of Pericardium of Utilized for the Closure of Ventricular Septal Defect. Postoperative Ventricular Septal Aneurysm. The Journal of Thoracic and Cardiovascular Surgery, 68, 209-218.

[19] Sinha, P., Zurakowski, D., Kumar, T.K., He, D., Rossi, C. and Jonas, R.A. (2012) Effects of Glutaraldehyde Concentration, Pretreatment Time, and Type of Tissue (Porcine versus Bovine) on Post Implantation Calcification. The Journal of Thoracic and Cardiovascular Surgery, 143, 224-227. https://doi.org/10.1016/j.jtcvs.2011.09.043

[20] Hjelms, E., Pohlner, P., Barratt-Boyes, B.G. and Gavin, J.B. (1981) Study of Autologous Pericardial Patch-Grafts in the Right Ventricular Outflow Tracts in Growing and Adult Dogs. The Journal of Thoracic and Cardiovascular Surgery, 81, 120-123.

[21] Boughner, D.R., Haldenby, M., Hui, A.J., Dunmore-Buyze, J., Talman, E.A. and Wan, W.K. (2000) The Pericardial Bioprosthesis: Altered Tissue Shear Properties Following Glutaraldehyde Fixation. The Journal of Heart Valve Disease, 9, 752-760.

[22] Tremblay, D., Zigras, T., Cartier, R., Leduc, L., Butany, J., Mongrain, R. and Leask, R.L. (2009) A Comparison of Mechanical Properties of Materials Used in Aortic Arch Reconstruction. The Annals of Thoracic Surgery, 88, 1484-1491. https://doi.org/10.1016/j.athoracsur.2009.07.023

[23] Miyazaki, T., Yamagishi, M., Nakashima, A., Fukae, K., Nakano, T., Yaku, H. and 
Kado, H. (2007) Expanded Polytetrafluoroethylene Valved Conduit and Patch with Bulging Sinuses in Right Ventricular Outflow Tract Reconstruction. The Journal of Thoracic and Cardiovascular Surgery, 134, 327-332. https://doi.org/10.1016/j.jtcvs.2007.03.030

[24] Yashir, B., Shoda, M., Tomizawa, Y., Manaka, T. and Hagiwara, N. (2012) LongTerm Results of a Cardiovascular Implantable Electronic Device Wrapped with an Expanded Polytetrafluoroethylene Sheet. Journal of Artificial Organs, 15, 244-249. https://doi.org/10.1007/s10047-012-0634-8

Submit or recommend next manuscript to SCIRP and we will provide best service for you:

Accepting pre-submission inquiries through Email, Facebook, LinkedIn, Twitter, etc. A wide selection of journals (inclusive of 9 subjects, more than 200 journals)

Providing 24-hour high-quality service

User-friendly online submission system

Fair and swift peer-review system

Efficient typesetting and proofreading procedure

Display of the result of downloads and visits, as well as the number of cited articles Maximum dissemination of your research work

Submit your manuscript at: http://papersubmission.scirp.org/

Or contact wjcs@scirp.org 